\title{
Statistical Modeling for Prediction of CCT Diagrams of Steels Involving Interaction of Alloying Elements
}

\author{
HENRY MARTIN (1), PETER AMOAKO-YIRENKYI, AARNE POHJONEN, \\ NANA K. FREMPONG, JUKKA KOMI, and MAHESH SOMANI
}

The interaction of different alloying elements has a significant impact on the mechanical and microstructural properties of steel products due to the thermodynamic and kinetic effect. This article presents a statistically developed and validated model for austenite decomposition during cooling, based on a set of experimental continuous cooling transformation diagrams available in literature. In the model, two-way interactions of the alloying elements are included as add-on terms, and the procedure for the analysis ensures there is no overfitting. The model can be used to predict phase transformation temperatures and critical cooling rates for the formation of polygonal ferrite, bainite or martensite for the production of steel.

https://doi.org/10.1007/s11663-020-01991-w

(c) The Minerals, Metals \& Materials Society and ASM International 2020

\section{INTRODUCTION}

STEEL is used in a wide variety of applications, which require specific mechanical properties. To achieve the desired properties, thermomechanical processing techniques are used, followed by continuous cooling, which results in specific microstructural evolution through phase transformation. This naturally influences the combined requisite property. During the processing, materials can be either deformed in austenitic state or as-cast from the melt and then cooled to room temperature. In the cooling stage, austenite can decompose to ferrite phase types roughly classified as (polygonal) ferrite, bainite and martensite. Since the different ferritic phases have a decisive influence on the mechanical properties, it is important to control the austenite

HENRY MARTIN is with the Center for Scientific and Technical Computing, National Institute for Mathematical Sciences, Kumasi, Ghana and also with the Department of Physics, Kwame Nkrumah University of Science and Technology, Kumasi, Ghana. Contact emails: hmartin@nims.edu.gh, hmartin@knust.edu.gh PETER AMOAKO-YIRENKYI is with the Center for Scientific and Technical Computing, National Institute for Mathematical Sciences and also with the Department of Mathematics, Kwame Nkrumah University of Science and Technology, Kumasi, Ghana. AARNE POHJONEN, JUKKA KOMI, and MAHESH SOMANI are with the Materials and Production Technology, University of Oulu, Pentti Kaiteran katu 1, 90014 Oulu, Finland. NANA K. FREMPONG is with the Center for Scientific and Technical Computing, National Institute for Mathematical Sciences and also with the Department of Statistics, Kwame Nkrumah University of Science and Technology, Kumasi, Ghana.

Manuscript submitted March 4, 2020; accepted September 25, 2020.

Article published online November 4, 2020. decomposition process. The most important factor affecting the austenite decomposition is the chemical composition of the steel and the applied cooling path.

The austenite decomposition is conventionally represented using time-temperature diagrams, either for holding at constant temperature (TTT, time temperature transformation diagrams) or for cooling at different rates (CCT, continuous cooling transformation diagrams). The TTT diagram can be used to calculate an estimate for the transformation start using Scheil's additivity rule, ${ }^{[1,2]}$ but since there is a considerable difference in the long-time isothermal holding and fast continuous cooling, the usage of the CCT diagram gives a better estimate of the transformation onset during rapid cooling. Since fast cooling rates are often used in steel production, predicting the decomposition of austenite using CCT diagrams was the subject of several earlier studies. ${ }^{[3-5]}$ Earlier studies $^{[6-8]}$ focused on the usage of an additive regression model of chemical composition as well as the cooling path effect for the start of transformation of ferrite, bainite and martensite, respectively. In these earlier studies, the interaction of different alloying elements was not taken into account; instead, the applied model assumed linear dependence on the alloying elements. Unfortunately, the physical interpretation of the overall transformation kinetic of undercooled austenite in steel is determined by several factors, such as the mobility of the compositional atoms participating in the transformation. This results in solute microsegregation, formation of precipitates, etc., which signifies interaction among the alloying elements. Therefore, using an additive model does not practically represent the physical phenomenon. 
To address this challenge, in this article we present a model that considers the interaction and quadratic dependence of alloying elements on the transformation onset. This provides better description of the experimental data since only the most significant interaction and quadratic alloying element terms were considered. This enables all the individual alloying elements to be significant for the time-dependent growth and response temperature. The efficiency of the current model has been further examined by fitting it with the CCT behavior of several steels, represented in References 9 and 10, which focus on molybdenum-containing steels.

\section{METHODOLOGY AND MODEL FORMULA- TION}

This article aims to develop a methodology to model, analyze and validate the characteristic curves for the onset of autensite decomposition into the three main primary undercooled phases, polygonal ferrite, bainite and martensite, which are normally present on the CCT diagrams. A range of molybdenum-containing steels with a wide variety of compositions and different combinations of alloying elements (two-way interaction) was used in fitting a linear model. The construction of longitudinal data (i.e., unbalanced time variation experimental data points $)^{[11]}$ in the field of statistical modeling and analysis was employed. ${ }^{[12-15]}$ The transformation start curves marking austenite decomposition were extracted from various CCT diagrams in the References 9 and 10, thus encompassing 68 curves of ferrite formation, 52 curves of bainite formation and 26 curves of martensite formation, as shown in Figure 1.

The chemical compositions shown in Table I give the range of mass concentration (in wt pet) of alloying elements used in this study.

\section{A. Model Formulation}

In the current study, our intention is to develop a statistical model and analyze and validate the data set describing a large number of CCT diagrams. An example of such a diagram for one steel is shown in Figure 1(d). The construction of statistically based models for phase transformation is not new as researchers in this field seek to simulate the behavior by drawing a relationship between the fractional weight of alloying elements, $(c)$, temperature, $(T)$ and time required for the undercooled formation of phases $(t)$. The alloying elements play a crucial role in the transformation, and recently it has become even more important to understand, ascertain and interpret their interaction to provide a better understanding of various microstructural phenomena, such as precipitation, microsegregation and other physical phenomena that occur in thermomechanical processing. The current article describes in detail the statistical models that were fitted to the experimental data and the approach that provided the best fit to the data.

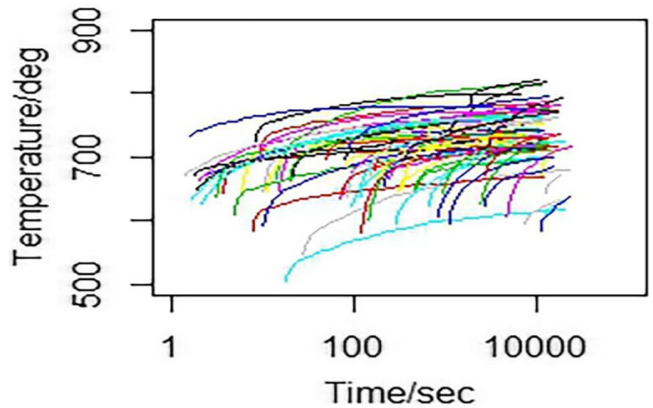

(a)

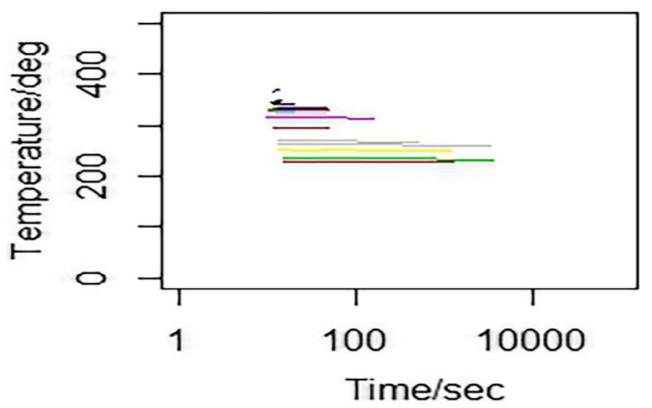

(c)

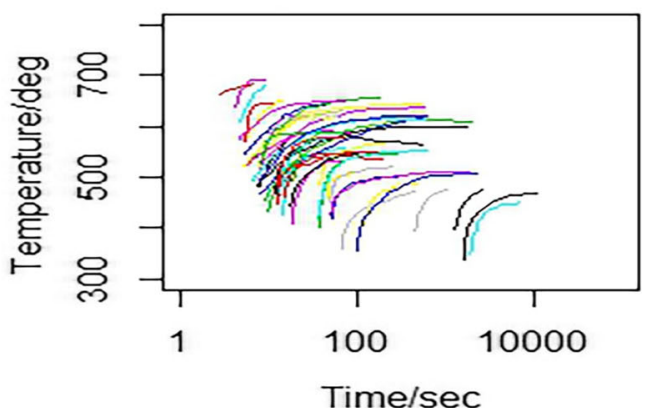

(b)

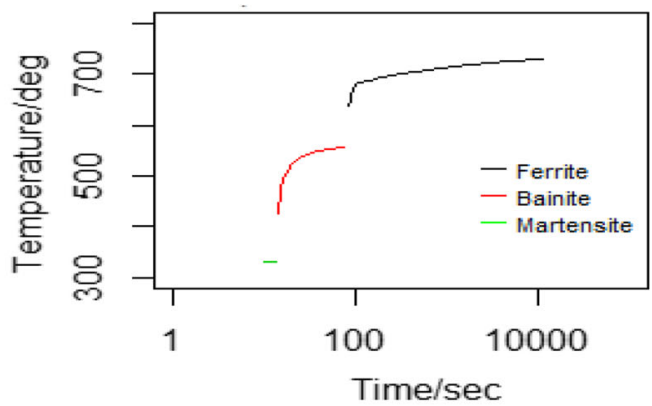

(d)

Fig. 1-Extracted experimental austenite decomposition start curves from various continuous cooling transformation (CCT) diagrams depicting (a) 68 ferrite start curves, (b) 52 bainite start curves, $(c) 26$ martensite start curves and $(d)$ corresponding curves for a single steel grade of 0.39 pet $\mathrm{C}-0.82$ pet $\mathrm{Mn}-0.26$ pet Si-0.21 pet Mo-1.0 pet Cr. 
Table I. Range of Mass Concentration (Weight Percent) of Elements

\begin{tabular}{|c|c|c|c|c|c|c|c|c|}
\hline Range & $\mathrm{C}$ & $\mathrm{Mn}$ & $\mathrm{Si}$ & Mo & $\mathrm{Ni}$ & $\mathrm{Cr}$ & $\mathrm{B}$ & $\mathrm{Co}$ \\
\hline \multicolumn{9}{|c|}{ Ferrite Onset Formation } \\
\hline Min & 0.097 & 0.32 & 0.16 & 0 & 0 & 0 & 0 & 0 \\
\hline Max & 0.41 & 1.47 & 1.5 & 0.95 & 4.45 & 3.76 & 0.006 & 3.9 \\
\hline \multicolumn{9}{|c|}{ Bainite Onset Formation } \\
\hline Min & 0.097 & 0.32 & 0.16 & 0 & 0 & 0 & 0 & 0 \\
\hline $\operatorname{Max}$ & 0.41 & 1.47 & 1.5 & 0.95 & 4.43 & 1.54 & 0.006 & 3.9 \\
\hline \multicolumn{9}{|c|}{ Martensite Onset Formation } \\
\hline Min & 0.3 & 0.68 & 0.26 & 0.21 & 0 & 0 & 0 & 0 \\
\hline $\operatorname{Max}$ & 0.41 & 1.45 & 1.5 & 0.82 & 4.43 & 1.54 & 0 & 0 \\
\hline
\end{tabular}

\section{Additive regression model}

For both polygonal ferrite and bainite, we first fitted the time coordinate $\left(t_{\mathrm{cr}}\right)$ corresponding to the fastest cooling rate that produces the given phase and then we fitted the coefficients $\alpha$ that describe the effect of alloying on the transformation temperature where $\beta$ is the intercept for the response temperature and $\delta$ is the amplitude for the inverse hyperbolic sine function. The different model formulations are given below. The implementation of Eqs. [AS1] and [AS2] represents the relation of the additive function of alloying elements and time-dependent growth of ferrite and bainite at a given response temperature. Equation [AS2] is a newly proposed model that contains a function to decrease the slope steepness for the onset of ferrite and bainite compared to the existing model of Eq. [AS1]. ${ }^{[6,16]}$ On the other hand, Eq. [AS3] concerns the formation of martensite, ${ }^{[8,17]}$ thus presenting time-independent growth since its response temperature is constant. Finally, Eq. [AS4] depicts the logarithmic time for the critical cooling rate in relation to the additive function of alloying elements that takes care of any form of skewness in Eqs. [AS1] and [AS2].

$$
\begin{gathered}
T=\beta+\sum_{l}^{k} \alpha_{l} c_{l}+\delta \operatorname{arcsinh}\left(t-t_{\mathrm{cr}}\right)+\varepsilon \\
T=\beta+\sum_{l}^{k} \alpha_{l} c_{l}+\delta \operatorname{arcsinh}\left(\log _{10}\left(1+t-t_{\mathrm{cr}}\right)\right)+\varepsilon \\
T=\beta+\sum_{l}^{k} \alpha_{l} c_{l}+\varepsilon \\
\log _{10} t_{\mathrm{cr}}=\beta+\sum_{l}^{k} \alpha_{l} c_{l}+\varepsilon
\end{gathered}
$$

\section{Interaction of alloying elements}

Alloying elements may have different interacting effects, either individually or in combination, from both a thermodynamic and kinetic point of view. Thermodynamics affects the driving force for the transformations and grain boundary segregation, and the speed of the transformation is affected by the atomic mobilities, which are also subjected to interactions. The Grossman formulation of hardenability used as todays' benchmark is based on all kinds of interaction terms. ${ }^{[18]}$

The atoms react with each other in any composition affecting the microstructural processes, such as nucleation, micro-segregation and precipitation in steel processing. Hence, it is prudent that terms defining the interaction of elements are included in the additive regression model. In statistical modeling this is formulated as follows: when the effect of a predictor on the response depends on another predictor ${ }^{[19-22]}$ or an interaction of a predictor variable with itself. The former is sometimes referred to as a multiplicative interaction ${ }^{[23,24]}$ and the latter a quadratic effect.

These additional terms have been ignored in most earlier models for the onset of phase formation in phase transformation of steel except for modeling C-Mn steel. ${ }^{[25,26]}$ Both the interaction of two different alloying elements as well as the quadratic effect of all individual alloying elements were employed for bainite formation. Also the quadratic effect of individual alloying elements was assessed in connection with martensite transformation in medium carbon S355 steel covering both the modeling of the start temperature as well as the prediction of mechanical properties. ${ }^{[27,28]}$

A two-way interaction, which incorporates either a single combination of two alloying elements or a quadratic effect of a single alloying element, or both, is added to the model in Eqs. [AS1] through [AS4] to obtain the interaction model shown in Eqs. [I1] through [14]. This is done using a stepwise regression method $^{[29,30]}$ to finalize a model that shows a reasonable effect, thus comprising good fitting using the model and the significance of all the individual alloying elements and their interaction in relation to the response temperature and time-dependent growth. ${ }^{[11]}$ 


$$
\begin{gathered}
T=\beta+\sum_{l}^{k} \alpha_{l} c_{l}+\delta \operatorname{arcsinh}\left(t-t_{\mathrm{cr}}\right)+\sum_{\substack{l, j \\
\langle l<j\rangle}}^{2} A_{l j} c_{l} c_{j}+\varepsilon \\
T=\beta+\sum_{l}^{k} \alpha_{l} c_{l}+\delta \operatorname{arcsinh}\left(\log _{10}\left(1+t-t_{\mathrm{cr}}\right)\right) \\
+\sum_{l, j}^{2} A_{l j} c_{l} c_{j}+\varepsilon \\
\quad\langle l<j\rangle \\
\quad T=\beta+\sum_{l}^{k} \alpha_{l} c_{l}+\sum_{l, j}^{2} B_{l j} c_{l} c_{j}+\varepsilon \\
\langle l=j\rangle \\
+[\mathrm{II} 2] \\
\log _{10} t_{\mathrm{cr}}=\beta+\sum_{l}^{k} \alpha_{l} c_{l}+\sum_{l, j}^{2} B_{l j} c_{l} c_{j}+\sum_{l, j}^{2} A_{l j} c_{l} c_{j}
\end{gathered}
$$

\section{RESULTS AND DISCUSSION}

The influence of combining alloy elements (i.e., two-way interaction) to reveal the impact of alloying elements on the existing phase transformation model (additive regression) describing the decomposition of austenite in steel was modeled, and analyzed as described in the previous section using mathematical and computational modeling and simulation tools $\left(\mathrm{SAS}^{[31]}, \mathrm{R}\right.$ and MATLAB), and statistical validation was conducted, as explained in Section III-E.

Table II shows the goodness-of-fit statistics for the additive model (Eqs. [AS1] through [AS3]) and the best alloying element interaction attained for the new model (Eqs. [I1] through [I3]).

From the statistics presented in Table II, the different selection criteria show how extensive (or little) information is lost for a model to obtain its observed data (thus the smaller the value, the better the fit). This, in effect, shows the quality of a model that is able to replicate the observed data, hence causing relatively less error in prediction. Four types of criteria ( $-2 \ell$, AIC, AICC and BIC) are used in this study mainly to show that an add-on of terms to the additive model (Eqs. [AS1] through [AS4]) is not causing any overfitting of the parameter estimate. ${ }^{[11]}$ The goodness-of-fit measurement shown in Table II depicts the criteria for all of the models displayed in the table. This indicates that the addition of an interaction term (thus combining alloying elements) gives the best fitness (i.e., the best model described by Eqs. [I 1] through [I4] and the parameters given in Tables IV, VI, VIII and X.

Also, it is clear from Figures 2, 3, and 4 that the data set with removed sample ids has a very good fitness measure. A global sensitivity analysis on studying the variation between steel grades (influence diagnostics) was conducted on the additive model (Eqs. [AS1] through [AS3]) employing Cook's distance $\left(D_{i}\right)$ statistics for the influence parameter estimate and CovRatio for the influence precision. ${ }^{[11]}$

Having known the influence of each steel grade on the parameter estimates for the additive model, a suitable decision was made to delete any sample that did not

\begin{tabular}{|c|c|c|c|c|}
\hline Models & $-2 \ell$ & AIC & AICC & $\mathrm{BIC}$ \\
\hline \multicolumn{5}{|c|}{ Onset of Ferrite Formation } \\
\hline AS1 & 10122.2 & 10146.2 & 10146.5 & 10172.3 \\
\hline AS2 & 10256.9 & 10280.9 & 10281.2 & 10307.0 \\
\hline I 1 & 10105.3 & 10131.3 & 10131.6 & 10159.6 \\
\hline I 2 & 10239.1 & 10265.1 & 10265.4 & 10293.4 \\
\hline \multicolumn{5}{|c|}{ Onset of Bainite Formation } \\
\hline AS1 & 8489.6 & 8513.6 & 8513.9 & 8536.6 \\
\hline AS2 & 8353.1 & 8377.1 & 8377.4 & 8400.0 \\
\hline I 1 & 8477.6 & 8505.6 & 8506.0 & 8532.4 \\
\hline I 2 & 8342.1 & 8370.1 & 8370.5 & 8396.9 \\
\hline \multicolumn{5}{|c|}{ Onset of Martensite Formation } \\
\hline AS3 & 10687.4 & 10711.4 & 10711.7 & 10738.1 \\
\hline $\mathrm{I} 3$ & 10239.1 & 10265.1 & 10265.4 & 10293.4 \\
\hline
\end{tabular}
give any positive contribution to the extension/adaptability of the model for any steel composition with the range shown in Table I.

Figures 2, 3, and 4 show the manner in which almost all the samples are at least contributing to the influence of the parameter estimate even though a few of them have a relatively higher impact than the others (thus $D$

Table II. Criteria (Fit Statistics) for Additive and Interaction Models for Polygonal Ferrite, Bainite and Martensite 
Influence Statistics for Temp

(a) Cook's D Fixed Effects

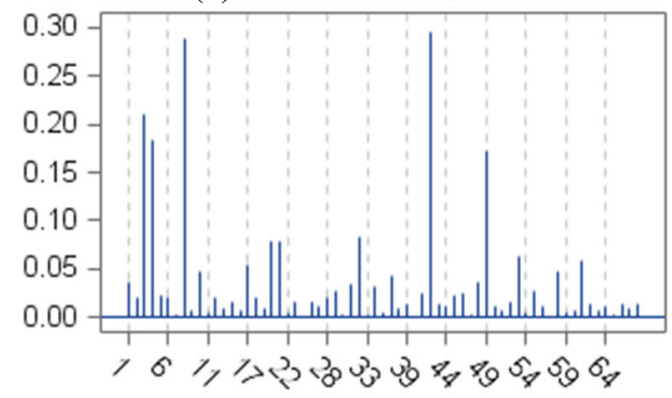

(c) CovRatio Fixed Effects

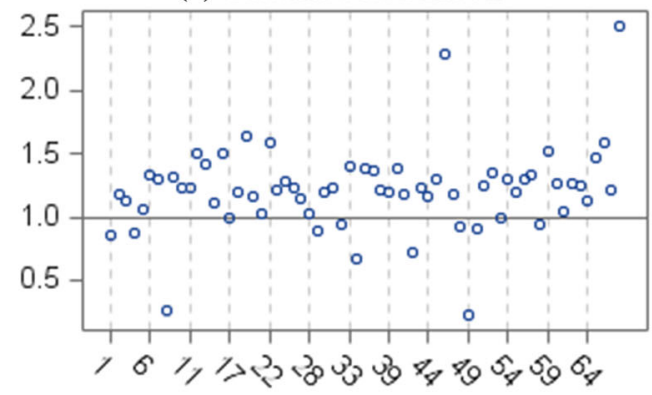

(b) Cook's D Covariance Parameters

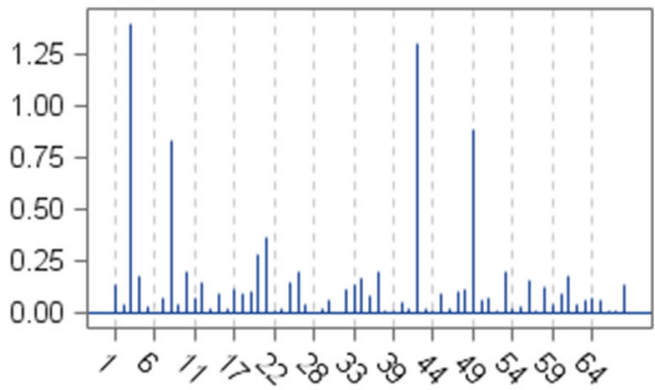

(d) CovRatio Covariance Parameters

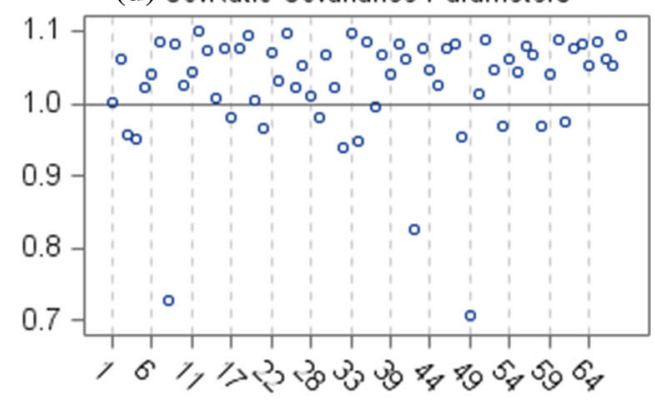

Deleted id

Fig. 2-Ferrite formation influence diagnostics of steel grades measuring (a) Cook's D fixed effects, (b) Cook's D covariance parameters, (c) CovRatio fixed effects, (d) CovRatio covariance parameters.

\section{Influence Statistics for Temp}

(a) Cook's D Fixed Effects

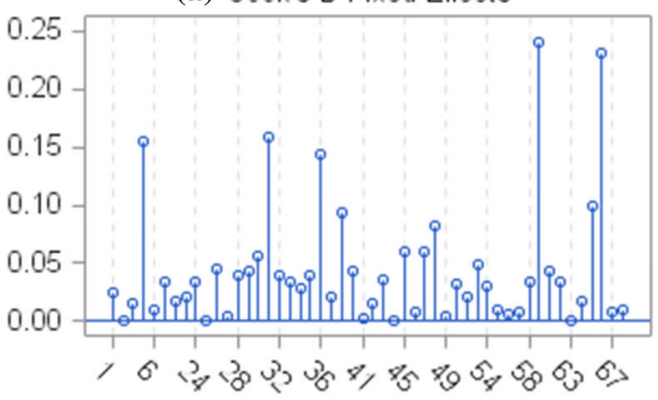

(c) CovRatio Fixed Effects

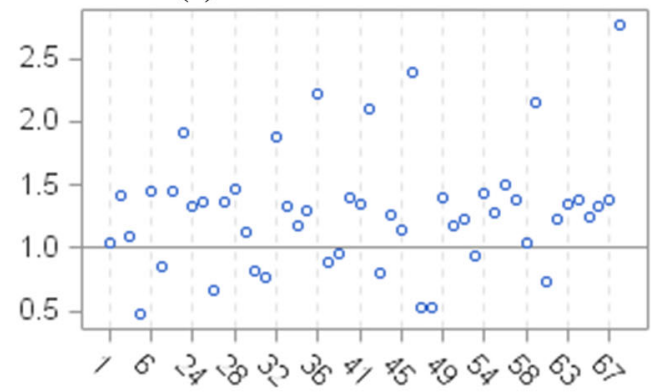

(b) Cook's D Covariance Parameters

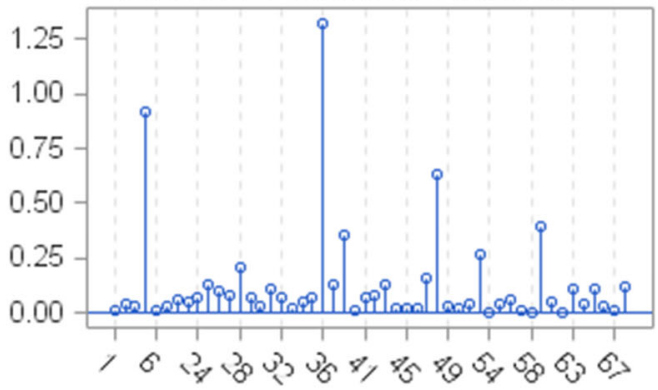

(d) CovRatio Covariance Parameters

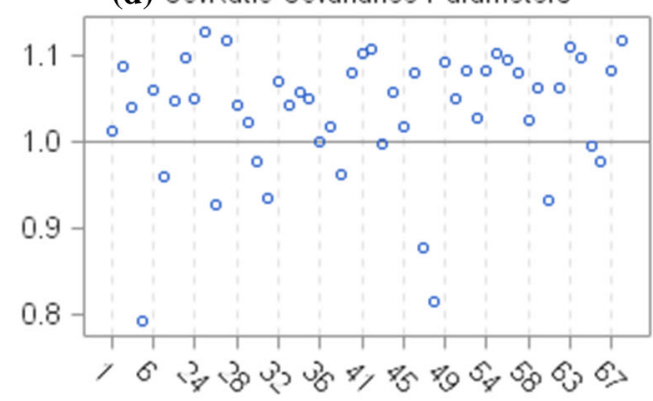

Deleted id

Fig. 3-Bainite formation influence diagnostics of steel grades measuring (a) Cook's D fixed effects, $(b)$ Cook's D covariance parameters, $(c)$ CovRatio fixed effects, $(d)$ CovRatio covariance parameters. 
values $>0.2$ ), which is less than in a very influential sample, as known by a cutoff value of 1 . Also, very few samples have a degradable precision, which does not

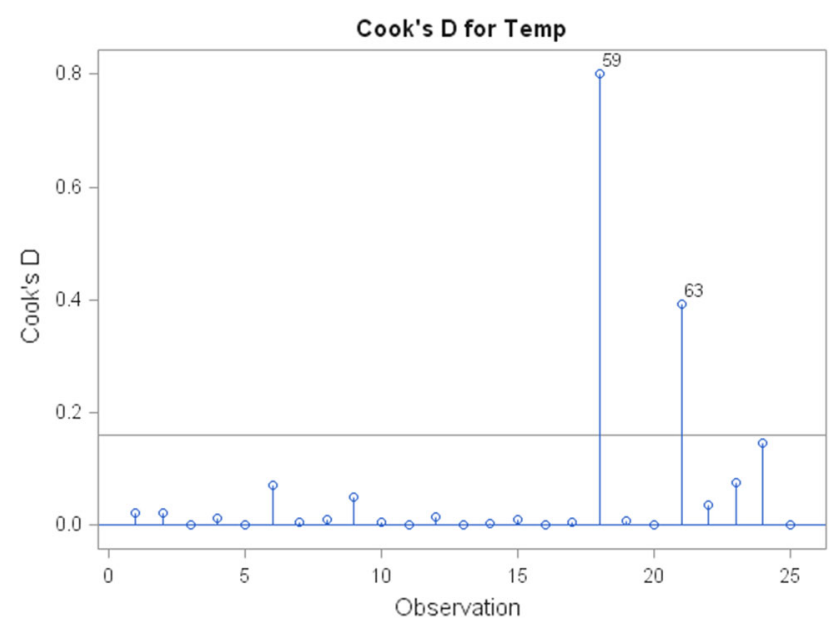

Fig. 4-Martensite formation influence on the diagnostics of steel grades. affect the estimates, given that their impact is not a threat to the estimates. Therefore, the full data set with some sample ids with much more degradable precision can be removed for a good data set to generate a usable, adaptable and extendable model with other steel compositions within the range provided.

We continue with testing the significance (thus $\mathrm{Pr}$ $<0.05$ ) of the alloying elements and their interaction while checking the goodness-of-fit statistics (thus $-2 \ell$, AIC, AICC and BIC) for each model (Eqs. [AS1] through [I4]). This numerical test comparison ascertains the combined alloying element (interaction) that affects the selected additive model positively. This was done chronologically for all the phases. For example, for the formation of polygonal ferrite, Tables III and IV indicate the significance of all the individual elements and their interaction in the models (thus the additive model (Eqs. [AS1] and [AS2]) and interaction model (Eqs. [I 1] and [I 2]) when the set of three sample ids was removed from the initial data set of ferrite formation). Again, this shows that the best fit is the interaction of the alloying element model (Eq. [I 1]) because apart from the interaction $\left(\mathrm{C}^{*} \mathrm{Ni}\right)$ itself showing a high

Table III. Parameter Estimates for the Polygonal Ferrite Additive Model

\begin{tabular}{|c|c|c|c|c|c|c|c|}
\hline \multicolumn{4}{|c|}{ AS1 } & \multicolumn{4}{|c|}{ AS2 } \\
\hline \multirow{2}{*}{ Effect } & \multicolumn{2}{|c|}{ Estimate } & \multirow{2}{*}{$\frac{\operatorname{Pr}>|t|}{<.0001}$} & \multirow{2}{*}{$\frac{\text { Effect }}{\text { intercept }}$} & \multicolumn{2}{|c|}{ Estimate } & \multirow{2}{*}{$\frac{\operatorname{Pr}>|t|}{<.0001}$} \\
\hline & $\beta$ & 773.59 & & & $\beta$ & 761.27 & \\
\hline $\mathrm{C}$ & $\alpha_{l}$ & -160.92 & $<.0001$ & $\mathrm{C}$ & $\alpha_{l}$ & -152.07 & $<.0001$ \\
\hline $\mathrm{Mn}$ & & -63.2933 & $<.0001$ & $\mathrm{Mn}$ & & -62.6536 & $<.0001$ \\
\hline $\mathrm{Si}$ & & 16.1381 & 0.0047 & $\mathrm{Si}$ & & 16.3829 & 0.0049 \\
\hline $\mathrm{Ni}$ & & -32.1110 & $<.0001$ & $\mathrm{Ni}$ & & -31.5361 & $<.0001$ \\
\hline Mo & & -19.5573 & 0.0078 & Mo & & -19.0940 & 0.0108 \\
\hline $\mathrm{Cr}$ & & -13.5218 & 0.0023 & $\mathrm{Cr}$ & & -13.5748 & 0.0027 \\
\hline B & & -2010.97 & 0.2373 & B & & -1454.33 & 0.4014 \\
\hline $\mathrm{Co}$ & & 6.0766 & 0.0679 & $\mathrm{Co}$ & & 5.8853 & 0.0831 \\
\hline$\delta$ & & 9.5706 & $<.0001$ & $\delta$ & & 44.4968 & $<.0001$ \\
\hline
\end{tabular}

$\alpha=0.05$, a drastic change of Pr values were obtained after the addition of the 2 way interaction of alloying elements.

Table IV. Parameter Estimates for the Polygonal Ferrite Interaction Model

\begin{tabular}{|c|c|c|c|c|c|c|c|}
\hline \multicolumn{4}{|c|}{ I1 } & \multicolumn{4}{|c|}{$\mathrm{I} 2$} \\
\hline \multirow{2}{*}{$\frac{\text { Effect }}{\text { Intercept }}$} & \multicolumn{2}{|c|}{ Estimate } & \multirow{2}{*}{$\frac{\operatorname{Pr}>|t|}{<.0001}$} & \multirow{2}{*}{$\frac{\text { Effect }}{\text { intercept }}$} & \multicolumn{2}{|c|}{ Estimate } & \multirow{2}{*}{$\frac{\operatorname{Pr}>|t|}{<.0001}$} \\
\hline & $\beta$ & 796.97 & & & $\beta$ & 785.75 & \\
\hline $\mathrm{C}$ & $\alpha_{l}$ & -243.37 & $<.0001$ & $\mathrm{C}$ & $\alpha_{l}$ & -238.33 & $<.0001$ \\
\hline Mn & & -55.5699 & $<.0001$ & $\mathrm{Mn}$ & & -54.5785 & $<.0001$ \\
\hline $\mathrm{Si}$ & & 18.4717 & 0.0003 & $\mathrm{Si}$ & & 18.8225 & 0.0003 \\
\hline $\mathrm{Ni}$ & & -53.9073 & $<.0001$ & $\mathrm{Ni}$ & & -54.3365 & $<.0001$ \\
\hline Mo & & -22.7219 & 0.0006 & Mo & & -22.4077 & 0.0009 \\
\hline $\mathrm{Cr}$ & & -15.3014 & 0.0001 & $\mathrm{Cr}$ & & -15.4388 & 0.0002 \\
\hline $\mathrm{B}$ & & -4182.67 & 0.0095 & $\mathrm{~B}$ & & -3727.63 & 0.0218 \\
\hline $\mathrm{Co}$ & & 8.3326 & 0.0059 & $\mathrm{Co}$ & & 8.2448 & 0.0071 \\
\hline $\mathrm{C}^{*} \mathrm{Ni}$ & $A_{l j}$ & 63.0462 & $<.0001$ & $\mathrm{C}^{*} \mathrm{Ni}$ & $A_{l j}$ & 65.9392 & $<.0001$ \\
\hline$\delta$ & & 9.5621 & $<.0001$ & $\delta$ & & 44.4567 & $<.0001$ \\
\hline
\end{tabular}

$\alpha=0.05$, a drastic change of $\operatorname{Pr}$ values were obtained after the addition of the 2 way interaction of alloying elements. 
significance value, it also changed the individual elements to significant (indicated with italic and boldface type in Tables III, IV, V, VI, VII, VIII, IX, X, XI, and XII).

\section{Ferrite}

In addition to undertaking the above numerical test comparison for all phases in this article, we further conducted an influential diagnostic test on the observation location space for the fastest cooling rate $\left(t_{\mathrm{cr}}\right)$ of ferrite and bainite in Eqs. [AS4] and [I4] and the martensite onset temperature in Eqs. [AS3] and [I3].

\section{Bainite}

The location of observations plays an important role in the estimation of predicted values, regression estimates and other model summary statistics such as the adjusted $R^{2}$ and root mean square error (RMSE) for an add-on parameter (thus the interaction). These are shown in Tables V, IX and XI for ferrite, bainite and martensite, respectively, supporting the argument in Tables VI, X and XII that the interaction of the alloying element yields better goodness of fit for the time of the critical cooling rate of ferrite and bainite as well as for the martensite onset temperature. As shown, Eq. [I4] has less error than additive regression Eq. [AS4]. Also, the variation from the predicted value (thus $\operatorname{Adj} R^{2}$ ) gets closer to 1 than in the case of the additive regression equation showing the extensiveness of an add-on interaction term fits the data well.

These influential diagnostic tests (predicted value, outlier and leverage) on the observation location space are shown in Figures 5, 6, 7, 8, 9, and 10 for polygonal ferrite, bainite and martensite, respectively.

Table V. Onset of the Ferrite Model Fit Statistics for the Time of the Critical Cooling Rate

\begin{tabular}{lccc}
\hline Model & $R^{2}$ & Adj $R^{2}$ & RMSE \\
\hline AS4 & 0.8054 & 0.7776 & 0.52844 \\
I4 & 0.9265 & 0.9095 & 0.33705 \\
\hline
\end{tabular}

\section{Martensite}

\section{A. Discussion of the Interaction of Alloying Elements}

The production of a new steel often requires heat treatment and a knowledge of the effect of alloying elements on the CCT diagram to achieve the desired final microstructure and mechanical properties. ${ }^{[32]}$ Alloying elements affect the details of the CCT diagram through their effect on thermodynamic and kinetic parameters controlling the formation of ferrite, bainite and martensite. ${ }^{[33,34]}$ These are highly dependent on the type, amount and interaction of alloying elements. The alloying elements can be in solid solution or in precipitates and thereby affect the prior austenite grain size and condition of the austenite dislocation structure following any thermomechanical treatment. ${ }^{[35]}$ Hence, they also affect the transformation start by changing the concentration of heterogeneous nucleation sites. ${ }^{[6]}$

Alloying elements can be classified according to their chemical properties as carbide formers: $\mathrm{Mn}, \mathrm{Cr}$ and $\mathrm{Mo}$; non-carbide formers: $\mathrm{Ni}$ and $\mathrm{Si}$; ferrite stabilizers: Mo and $\mathrm{Si}$; austenite stabilizers: Mn, C and Ni. Reference 35 gives a qualitative description and physical explanation of all the single alloying element effects, which agree with our results. $\mathrm{C}, \mathrm{Mn}, \mathrm{Cr}$ and $\mathrm{Mo}$ retard the phase transformation while $\mathrm{Si}$ promotes ferrite formation.

The nonlinearity relationship between the heat treatment and the alloying elements is a known characteristic that specifies the interactions between the alloying elements. ${ }^{[36]}$ This description was also confirmed in Reference 37 with the occurrence of concave regions signifying the interaction between alloying elements either enhancing or reducing each other's effects. This agrees with our results as Table IV further shows that the analysis of the interaction of $\mathrm{C}-\mathrm{Ni}$ in ferrite transformation starts with the physical contribution of high hardenability. The positive $\mathrm{Ni} * \mathrm{C}$ term and high statistically significant value mean that $\mathrm{C}$ depresses the

Table VI. Parameter Estimates of the Time for the Critical Cooling Rate Models for Ferrite Onset

\begin{tabular}{|c|c|c|c|c|c|c|c|}
\hline \multicolumn{4}{|c|}{ AS4 } & \multicolumn{4}{|c|}{ I4 } \\
\hline \multirow{2}{*}{$\frac{\text { Effect }}{\text { Intercept }}$} & \multicolumn{2}{|c|}{ Estimate } & \multirow{2}{*}{$\begin{array}{r}\operatorname{Pr}>|t| \\
0.0034\end{array}$} & \multirow{2}{*}{$\begin{array}{c}\text { Effect } \\
\text { intercept }\end{array}$} & \multicolumn{2}{|c|}{ Estimate } & \multirow{2}{*}{$\begin{array}{l}\operatorname{Pr}>|t| \\
<.0001\end{array}$} \\
\hline & $\beta$ & -1.5962 & & & $\beta$ & -2.2898 & \\
\hline $\mathrm{C}$ & $\alpha_{l}$ & 2.5496 & 0.0275 & $\mathrm{C}$ & $\alpha_{l}$ & 3.0372 & 0.0002 \\
\hline $\mathrm{Mn}$ & & 1.15167 & 0.0037 & $\mathrm{Mn}$ & & 1.5427 & $<.0001$ \\
\hline $\mathrm{Si}$ & & 0.0102 & 0.9601 & $\mathrm{Si}$ & & 0.06265 & 0.6332 \\
\hline $\mathrm{Ni}$ & & 0.4597 & $<.0001$ & $\mathrm{Ni}$ & & 0.2723 & $<.0001$ \\
\hline Mo & & 3.2113 & $<.0001$ & Mo & & 6.5357 & $<.0001$ \\
\hline $\mathrm{Cr}$ & & 0.5868 & 0.0004 & $\mathrm{Cr}$ & & 0.4426 & 0.0002 \\
\hline B & & 320.62 & $<.0001$ & B & & 827.7659 & $<.0001$ \\
\hline $\mathrm{Co}$ & & -0.1705 & 0.1665 & $\mathrm{Co}$ & & -11.69184 & 0.0418 \\
\hline - & $B_{i j}$ & - & - & Mo*Mo & $B_{l j}$ & -4.90195 & $<.0001$ \\
\hline- & & - & - & $\mathrm{B} * \mathrm{~B}$ & & -89309 & 0.0045 \\
\hline - & $A_{l j}$ & - & - & $\mathrm{Mo} * \mathrm{Ni}$ & $A_{l j}$ & 0.6626 & 0.0011 \\
\hline - & & - & - & $\mathrm{C}^{*} \mathrm{Co}$ & & 29.6718 & 0.0416 \\
\hline
\end{tabular}

$\alpha=0.05$, a drastic change of Pr values were obtained after the addition of the 2 way interaction of alloying elements. 
(a) Observed by Predicted for log_tcr

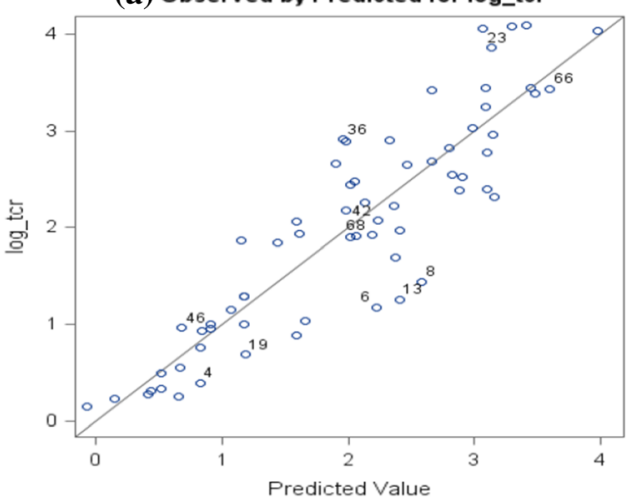

(b) Outlier and Leverage Diagnostics for $\log _{-}$ter

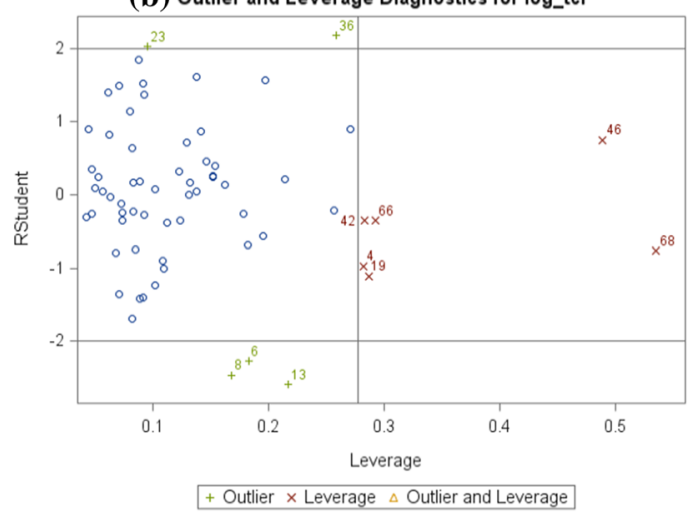

Fig. 5-Ferrite onset time of the critical cooling rate for additive model indicating $(a)$ comparison of the predicted fit to data and $(b)$ outlier and leverage diagnostics.

(a) Observed by Predicted for log_tcr

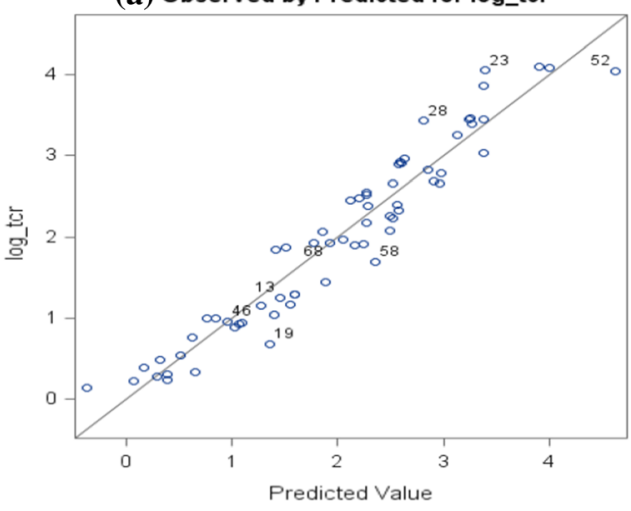

(b) Outlier and Leverage Diagnostics for $\log _{\text {t }}$ ter

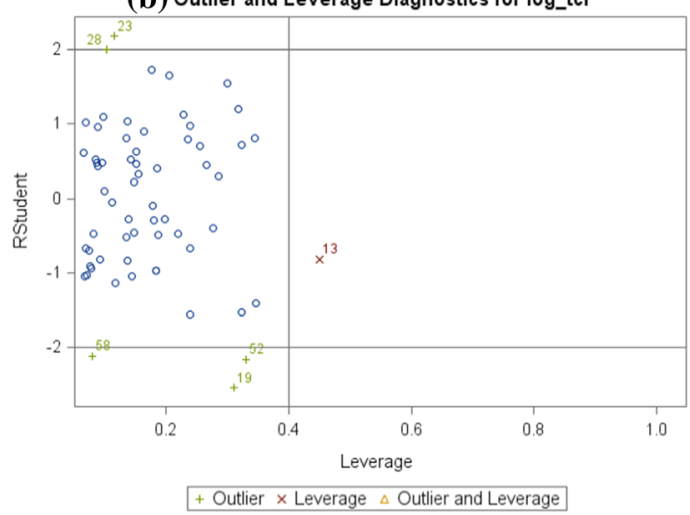

Fig. 6-Ferrite onset time of the critical cooling rate for the interaction model indicating $(a)$ comparison of the predicted fit to data and $(b)$ outlier and leverage diagnostics.

start of the ferrite reaction less in the presence of $\mathrm{Ni}$ than otherwise. This interaction further acknowledges the hardenability modification of $\mathrm{B}$ and $\mathrm{Co}^{[10,38]}$ also with a statistically significant value. Table VI continues with the time for the critical cooling rate. This again indicates the non-linearity with the interaction of C-Co, Mo-Ni, $\mathrm{Mo}^{2}$ and $\mathrm{B}^{2}$. All of these interactions obtained statistically significant values, which caused $\mathrm{Co}$ also to be statistically significant. $\mathrm{Mo}^{2}$ and $\mathrm{B}^{2}$ indicate a way of balancing the hardenability of the steel. This has been explained with boron being the main factor of hardenability as it reduces the free energy of austenite grain boundaries due to segregation, retarding the nucleation of ferrite and bainite. ${ }^{[39]}$ This result of the interaction between Mo and Ni causes an increase in the delay of the start of ferrite transformation leading to the manifestation of hardenability. The presence of the interaction between $\mathrm{C}$ and $\mathrm{Co}$ introduces a faster austenite transformation, which brings in a lower hardenability. Therefore, the C-Co interaction was a means of adjusting the hardenability contributed from the $\mathrm{Mo}^{2}$ interaction in the ferrite.
In the case of the bainite onset parameters shown in Table VIII and Reference 10, the References 40, 41, and 42 confirms our results of an interaction of alloying elements with several explanations: Nickel is known to reduce the critical cooling rates of bainite while silicon increases the critical cooling rate of ferrite and bainite, hence the report that the effect of molybdenum is enhanced by nickel. ${ }^{[37]}$ Also, Mo exerts a solute drag effect. ${ }^{[43]}$ This is consistent with the analysis of our results indicating the $\mathrm{Ni}-\mathrm{Mo}$ and $\mathrm{Si}-\mathrm{Mo}$ interaction. This shows that the balance of the reaction effect caused $\mathrm{Si}$ in Table VII to be statistically significant in Table VIII. Manganese being a weak carbide-forming element and an austenite stabilizer enhances the effect of $\mathrm{C}$ by increasing carbon solubility in austenite. Therefore, the $\mathrm{C}-\mathrm{Mn}$ interaction is understood to increase the incubation time for bainite transformation. [44]

In the case of martensite temperature onset parameters, $\mathrm{Mn}^{2}$ obtaining a statistically significant value causes Mn to also be significant in Table XII. Manganese is well known to also increase martensite hardenability because of its partitioning between the 
(a) Observed by Predicted for log_tcr

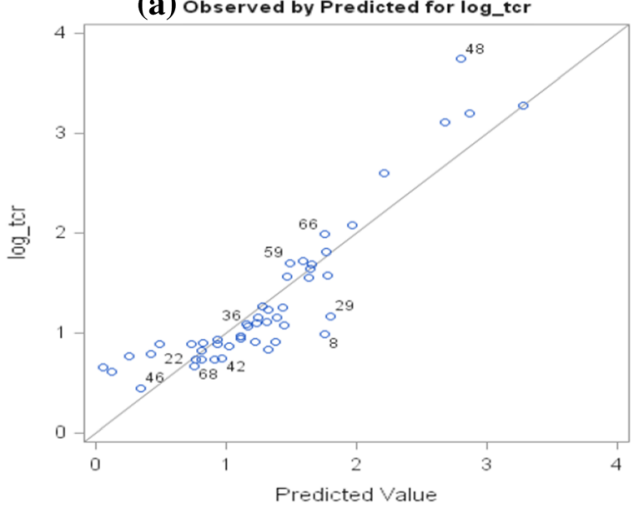

(b) Outlier and Leverage Diagnostics for log_tcr

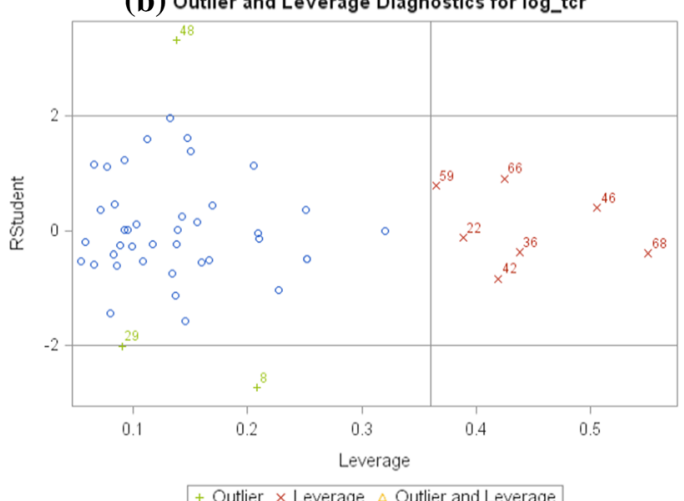

+ Outlier $\times$ Leverage A Outlier and Leverage

Fig. 7-Bainite onset time of the critical cooling rate for the additive model indicating (a) comparison of the predicted fit to data and (b) outlier and leverage diagnostics.

(a) Observed by Predicted for log_tcr

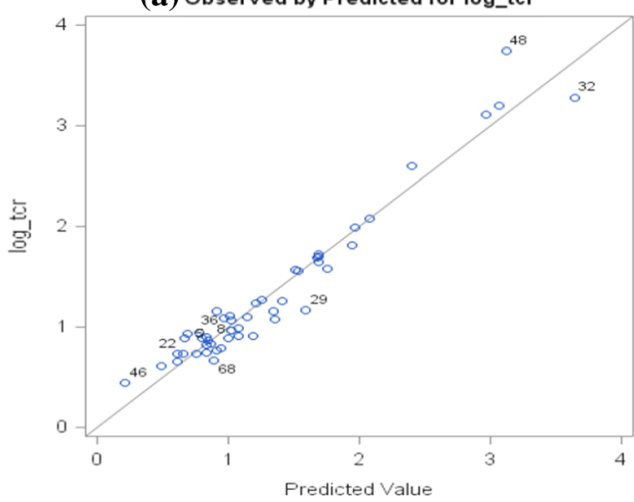

(b) Outlier and Leverage Diagnostics for log_tcr

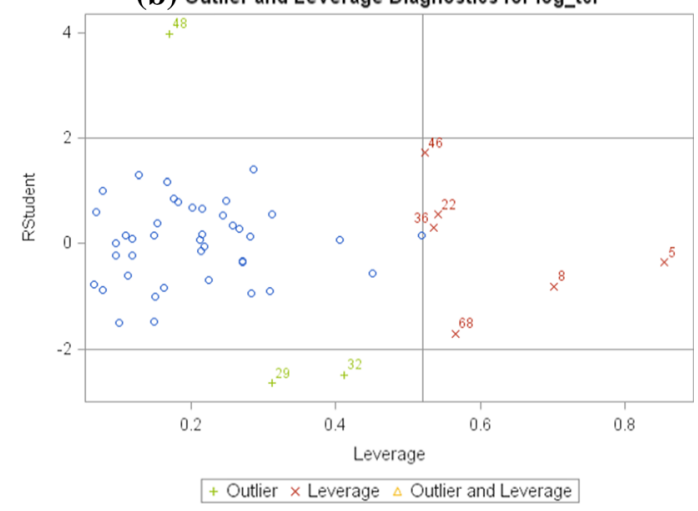

Fig. 8-Bainite onset time of the critical cooling rate for the interaction model indicating $(a)$ comparison of the predicted fit to data and $(b)$ outlier and leverage diagnostics.

(a) Observed by Predicted for Temp

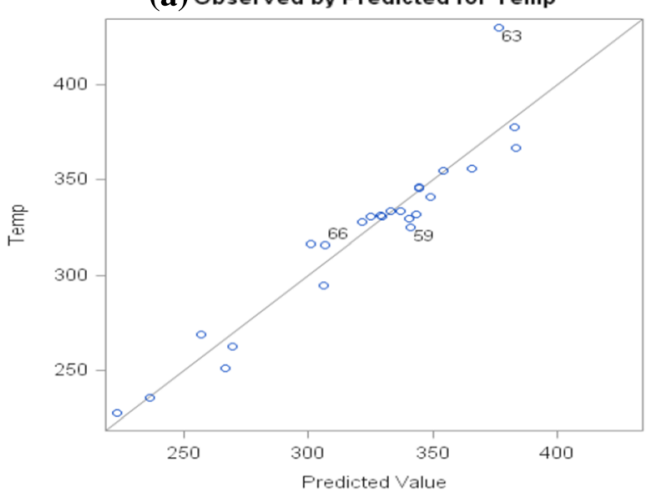

(b) Outlier and Leverage Diagnostics for Temp

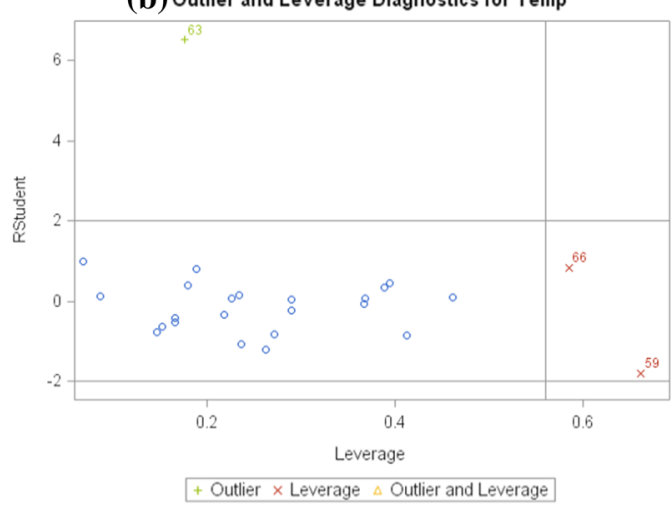

Fig. 9-Martensite temperature of onset for the additive model indicating (a) comparison of the predicted fit to data and (b) outlier and leverage diagnostics.

austenite and ferrite during transformation, inducing microsegregation and bands of course in the hot-rolled product. ${ }^{[45]}$ Also, manganese is known to move the phase region of martensite to low temperature. The non-linearity effect of manganese from our results agrees with References 17 and 37. Finally, we think an analysis with an increased order of interaction to cater for the single insignificant value that was not achieved is needed. An example is $\mathrm{Si}, \mathrm{Co}$ and Mo in Tables VI, X and XII, respectively. 
(a) Observed by Predicted for Temp

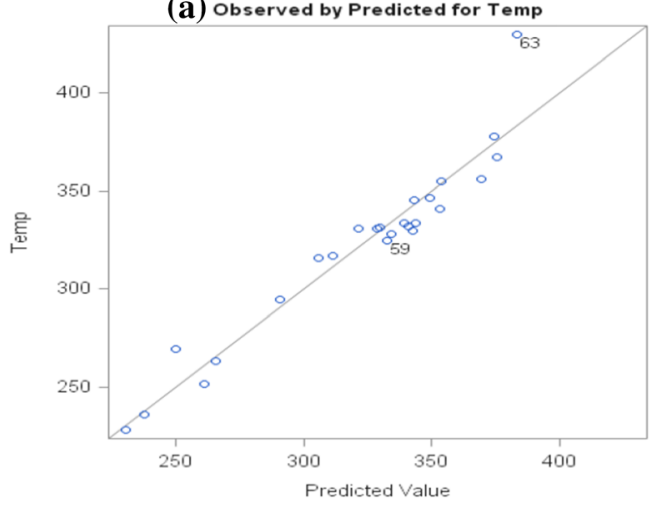

(b) Outlier and Leverage Diagnostics for Temp

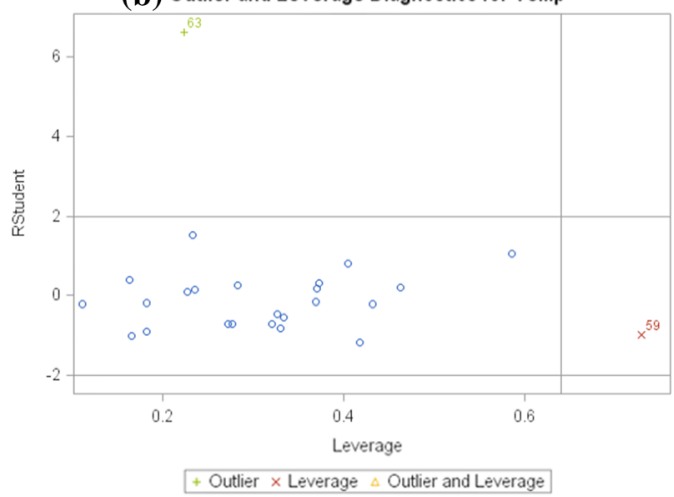

Fig. 10-Martensite temperature of onset for the interaction model indicating $(a)$ comparison of the predicted fit to data and $(b)$ outlier and leverage diagnostics.

Table VII. Parameter Estimates for the Onset Bainite Additive Model

\begin{tabular}{|c|c|c|c|c|c|c|c|}
\hline \multicolumn{4}{|c|}{ AS1 } & \multicolumn{4}{|c|}{ AS2 } \\
\hline \multirow{2}{*}{$\frac{\text { Effect }}{\text { Intercept }}$} & \multicolumn{2}{|c|}{ Estimate } & \multirow{2}{*}{$\begin{array}{l}\operatorname{Pr}>|t| \\
<.0001\end{array}$} & \multirow{2}{*}{$\frac{\text { Effect }}{\text { intercept }}$} & \multicolumn{2}{|c|}{ Estimate } & \multirow{2}{*}{$\frac{\operatorname{Pr}>|t|}{<.0001}$} \\
\hline & $\beta$ & 899.61 & & & $\beta$ & 886.50 & \\
\hline $\mathrm{C}$ & $\alpha_{l}$ & -551.68 & $<.0001$ & $\mathrm{C}$ & $\alpha_{l}$ & -539.14 & $<.0001$ \\
\hline $\mathrm{Mn}$ & & -102.83 & $<.0001$ & $\mathrm{Mn}$ & & -102.27 & $<.0001$ \\
\hline $\mathrm{Si}$ & & -6.7191 & 0.5461 & $\mathrm{Si}$ & & -6.2975 & 0.5650 \\
\hline $\mathrm{Ni}$ & & -60.2258 & $<.0001$ & $\mathrm{Ni}$ & & -58.3767 & $<.0001$ \\
\hline Mo & & -183.14 & $<.0001$ & Mo & & -183.64 & $<.0001$ \\
\hline $\mathrm{Cr}$ & & -89.9940 & $<.0001$ & $\mathrm{Cr}$ & & -90.9165 & $<.0001$ \\
\hline B & & -24458 & $<.0001$ & $\mathrm{~B}$ & & $-23,816$ & $<.0001$ \\
\hline $\mathrm{Co}$ & & 25.6220 & $<.0001$ & $\mathrm{Co}$ & & 25.8393 & $<.0001$ \\
\hline$\delta$ & & 18.8214 & $<.0001$ & $\delta$ & & 74.8521 & $<.0001$ \\
\hline
\end{tabular}

Table VIII. Parameter Estimates for the Onset Bainite Interaction Model

\begin{tabular}{|c|c|c|c|c|c|c|c|}
\hline \multicolumn{4}{|c|}{ I 1} & \multicolumn{4}{|c|}{ I 2} \\
\hline \multirow{2}{*}{$\frac{\text { Effect }}{\text { Intercept }}$} & \multicolumn{2}{|c|}{ Estimate } & \multirow{2}{*}{$\frac{\operatorname{Pr}>|t|}{<.0001}$} & \multirow{2}{*}{$\frac{\text { Effect }}{\text { intercept }}$} & \multicolumn{2}{|c|}{ Estimate } & \multirow{2}{*}{$\frac{\operatorname{Pr}>|t|}{<.0001}$} \\
\hline & $\beta$ & 871.93 & & & $\beta$ & 859.24 & \\
\hline $\mathrm{C}$ & $\alpha_{l}$ & -572.32 & $<.0001$ & $\mathrm{C}$ & $\alpha_{l}$ & -559.36 & $<.0001$ \\
\hline $\mathrm{Mn}$ & & -97.5479 & $<.0001$ & $\mathrm{Mn}$ & & -96.4405 & $<.0001$ \\
\hline $\mathrm{Si}$ & & 44.3756 & 0.0507 & $\mathrm{Si}$ & & 43.5439 & $\mathbf{0 . 0 5 3 7}$ \\
\hline $\mathrm{Ni}$ & & -46.6330 & $<.0001$ & $\mathrm{Ni}$ & & -45.9549 & $<.0001$ \\
\hline Mo & & -117.56 & $<.0001$ & Mo & & -120.91 & $<.0001$ \\
\hline $\mathrm{Cr}$ & & -86.8119 & $<.0001$ & $\mathrm{Cr}$ & & -87.8734 & $<.0001$ \\
\hline B & & -25252 & $<.0001$ & $\mathrm{~B}$ & & -24516 & $<.0001$ \\
\hline $\mathrm{Co}$ & & 23.0973 & 0.0001 & Co & & 23.6204 & $<.0001$ \\
\hline $\mathrm{Si} * \mathrm{Mo}$ & $A_{l j}$ & -102.70 & 0.0084 & Si*Mo & $A_{l j}$ & -99.7102 & 0.0100 \\
\hline Ni*Mo & & -43.1331 & 0.0114 & $\mathrm{Ni}^{*} \mathrm{Mo}$ & & -39.0975 & 0.0202 \\
\hline$\delta$ & & 18.8267 & $<.0001$ & $\delta$ & & 74.8666 & $<.0001$ \\
\hline
\end{tabular}

$\alpha=0.05$, a drastic change of $\operatorname{Pr}$ values were obtained after the addition of the 2 way interaction of alloying elements.

\section{B. Model Validation}

Model validation is the task of confirming that the parameter estimates from the statistical model are acceptable by obtaining a response variable with less error using a data-generating process. This process decides whether the numerical results quantifying the hypothesized relationships between variables (i.e., significance of alloying elements and their interaction) obtained from the regression analysis are acceptable as a descriptions of the data. This is based on the data that 
were used in the construction of the model, which involve analyzing the goodness of fit of the model. We performed this test using five different sample ids with an in-house MATLAB code to generate Figures 11, 12, 13,14 , and 15 .

The construction of the best model (interaction of alloying elements) can be attained by replacing the parameter estimates (i.e., $\alpha_{l}, \beta, \delta, B_{l j}$ and $A_{l j}$ ) in Eqs. [I1] through [I4] with the value obtained by the statistical modeling and analysis given in Tables IV, VI, VIII and $\mathrm{X}$.

\section{CONCLUSION}

The combined effects of pairs of alloying elements (two-way interactions) in the prediction of CCT diagrams has been quantitatively modeled, analyzed and validated. The approach used provides a novel way of constructing a model to predict austenitic decomposition for use in steel development. Unlike with previous models, ${ }^{[6,26,46]}$ this article has shown that an add-on term improves the fit without causing overfitting. Finally, apart from the add-on terms (interaction of alloying elements, i.e., two way or quadratic) themselves showing high significance values $(\operatorname{Pr}<.0001)$, it also improved the significance of some of the individual elements and further caused others to be significant $(\operatorname{Pr}<0.05)$ to the response temperature and critical cooling rate. We found that, out of the tested models, the best description for the CCT start curves is given by the following equations: The ferrite start curve $T_{\mathrm{f}}(t)$ is described by Eq. [1]

Table IX. Onset of Bainite Model Fit Statistics for the Time of the Critical Cooling Rate

\begin{tabular}{lccc}
\hline Model & $R^{2}$ & Adj $R^{2}$ & RMSE \\
\hline AS4 & 0.8229 & 0.7884 & 0.34108 \\
I4 & 0.9434 & 0.9251 & 0.20299 \\
\hline
\end{tabular}

$$
\begin{aligned}
T_{\mathrm{f}}(t)= & 796.97-243.37 \mathrm{C}-55.70 \mathrm{Mn}+18.47 \mathrm{Si} \\
& -53.91 \mathrm{Ni}-22.72 \mathrm{Mo}-15.30 \mathrm{Cr}-4182.67 \mathrm{~B} \\
& +8.33 \mathrm{Co}+63.05 \mathrm{CNi}+9.56 \operatorname{arcsinh}\left(t-t_{\mathrm{cr}, \mathrm{f}}\right)
\end{aligned}
$$

where $t \geq t_{\text {cr.f. }}$ The critical cooling time for ferrite, $t_{\text {cr,f }}$, is obtained from Eq. [2]

$$
\begin{aligned}
\log _{10}\left(t_{\mathrm{cr}, \mathrm{f}}\right)= & -2.29+3.04 \mathrm{C}+1.54 \mathrm{Mn}+0.063 \mathrm{Si} \\
& +0.27 \mathrm{Ni}+6.54 \mathrm{Mo}+0.44 \mathrm{Cr}+827.77 \mathrm{~B} \\
& -11.69 \mathrm{Co}-4.90 \mathrm{Mo}^{2}-89309 \mathrm{~B}^{2} \\
& +0.66 \mathrm{MoNi}+29.67 \mathrm{CCo}
\end{aligned}
$$

The bainite start curve $T_{\mathrm{b}}(t)$ is described by Eq. [3]

$$
\begin{aligned}
T_{\mathrm{b}}(t)= & 859.24-559.36 \mathrm{C}-96.44 \mathrm{Mn}+43.54 \mathrm{Si} \\
& -45.95 \mathrm{Ni}-120.91 \mathrm{Mo}-87.87 \mathrm{Cr}-24516 \mathrm{~B} \\
& +23.62 \mathrm{Co}-99.71 \mathrm{SiMo}-39.10 \mathrm{NiMo} \\
& +74.87 \operatorname{arcsinh}\left(\log _{10}\left(1+t-t_{\mathrm{cr}, \mathrm{b}}\right)\right)
\end{aligned}
$$

\begin{tabular}{|c|c|c|c|c|c|c|c|}
\hline \multicolumn{4}{|c|}{ AS4 } & \multicolumn{4}{|c|}{$\mathrm{I} 4$} \\
\hline \multirow{2}{*}{$\frac{\text { Effect }}{\text { Intercept }}$} & \multicolumn{2}{|c|}{ Estimate } & \multirow{2}{*}{$\frac{\operatorname{Pr}>|t|}{0.0032}$} & \multirow{2}{*}{$\frac{\text { Effect }}{\text { Intercept }}$} & \multicolumn{2}{|r|}{ Estimate } & \multirow{2}{*}{$\frac{\operatorname{Pr}>|t|}{0.0029}$} \\
\hline & $\beta$ & -1.3302 & & & $\beta$ & -8.19007 & \\
\hline $\mathrm{C}$ & $\alpha_{l}$ & 4.6781 & $<.0001$ & $\mathrm{C}$ & $\alpha_{l}$ & 20.4879 & 0.0039 \\
\hline $\mathrm{Mn}$ & & 0.2414 & 0.4600 & $\mathrm{Mn}$ & & 7.28762 & 0.0214 \\
\hline $\mathrm{Si}$ & & 0.14070 & 0.3939 & $\mathrm{Si}$ & & 0.30940 & 0.0036 \\
\hline $\mathrm{Ni}$ & & 0.5196 & $<.0001$ & $\mathrm{Ni}$ & & 0.66200 & $<.0001$ \\
\hline Mo & & 0.8394 & 0.0017 & Mo & & 1.16926 & $<.0001$ \\
\hline $\mathrm{Cr}$ & & 0.4880 & 0.0002 & $\mathrm{Cr}$ & & 0.73920 & $<.0001$ \\
\hline $\mathrm{B}$ & & 150.2221 & 0.0025 & $\mathrm{~B}$ & & 2418.1819 & $<.0001$ \\
\hline $\mathrm{Co}$ & & -0.17431 & 0.0534 & $\mathrm{Co}$ & & -0.10468 & 0.0646 \\
\hline- & $B_{l j}$ & - & - & $\mathrm{B} * \mathrm{~B}$ & $B_{l j}$ & -157312 & $<.0001$ \\
\hline- & $A_{l j}$ & - & - & $\mathrm{Ni} * \mathrm{~B}$ & $A_{l j}$ & -70.8405 & $<.0001$ \\
\hline- & & - & - & $\mathrm{Mn} * \mathrm{~B}$ & & -1650.1143 & 0.0038 \\
\hline 一 & & - & - & $\mathrm{C}^{*} \mathrm{Mn}$ & & -17.1969 & 0.0345 \\
\hline
\end{tabular}

where $t \geq t_{\mathrm{cr}, \mathrm{b}}$. The critical cooling time for bainite, $t_{\mathrm{cr}, \mathrm{b}}$, is obtained from Eq. [4]

$$
\begin{aligned}
\log _{10}\left(t_{\mathrm{cr}, \mathrm{b}}\right)= & -8.19+20.49 \mathrm{C}+7.29 \mathrm{Mn}+0.31 \mathrm{Si} \\
& +0.66 \mathrm{Ni}+1.17 \mathrm{Mo}+0.74 \mathrm{Cr}+2418.18 \mathrm{~B} \\
& -0.10 \mathrm{Co}-70.84 \mathrm{NiB}-1650.11 \mathrm{MnB} \\
& -17.20 \mathrm{CMn}-157,312 \mathrm{~B}^{2},
\end{aligned}
$$

and the martensite start temperature is given by Eq. [5]

Table XI. Onset of Martensite Model AS3 fit Statistics for Temperature

\begin{tabular}{lccc}
\hline Model & $R^{2}$ & Adj $R^{2}$ & RMSE \\
\hline AS3 & 0.9022 & 0.8696 & 16.40373 \\
I3 & 0.9238 & 0.8925 & 14.89245 \\
\hline
\end{tabular}

Table X. Parameter Estimates of the Time for the Critical Cooling Rate Models for Bainite Onset 
Table XII. Parameter Estimates for the Onset Martensite Additive and Interaction Models

\begin{tabular}{|c|c|c|c|c|c|c|c|}
\hline \multicolumn{4}{|c|}{ AS3 } & \multicolumn{4}{|c|}{$\mathrm{I} 3$} \\
\hline \multirow{2}{*}{$\frac{\text { Effect }}{\text { Intercept }}$} & \multicolumn{2}{|c|}{ Estimate } & \multirow{2}{*}{$\begin{array}{l}\operatorname{Pr}>|t| \\
<.0001\end{array}$} & \multirow{2}{*}{$\frac{\text { Effect }}{\text { intercept }}$} & \multicolumn{2}{|c|}{ Estimate } & \multirow{2}{*}{$\frac{\operatorname{Pr}>|t|}{0.0015}$} \\
\hline & $\beta$ & 624.7086 & & & $\beta$ & 406.6550 & \\
\hline $\mathrm{C}$ & $\alpha_{l}$ & -671.3039 & $<.0001$ & $\mathrm{C}$ & $\alpha_{l}$ & -843.1093 & $<.0001$ \\
\hline $\mathrm{Mn}$ & & -22.2523 & 0.3219 & $\mathrm{Mn}$ & & 528.0025 & 0.0506 \\
\hline $\mathrm{Si}$ & & -20.1481 & 0.0711 & $\mathrm{Si}$ & & -20.5010 & 0.0463 \\
\hline $\mathrm{Ni}$ & & -25.4520 & $<.0001$ & $\mathrm{Ni}$ & & -20.79077 & $<.0001$ \\
\hline Mo & & 14.44503 & 0.5745 & Mo & & 20.55019 & 0.3860 \\
\hline $\mathrm{Cr}$ & & -17.6135 & 0.1008 & $\mathrm{Cr}$ & & -19.50909 & 0.0508 \\
\hline - & $B_{l j}$ & - & - & $\mathrm{Mn} * \mathrm{Mn}$ & $B_{l j}$ & -250.93470 & 0.0420 \\
\hline
\end{tabular}

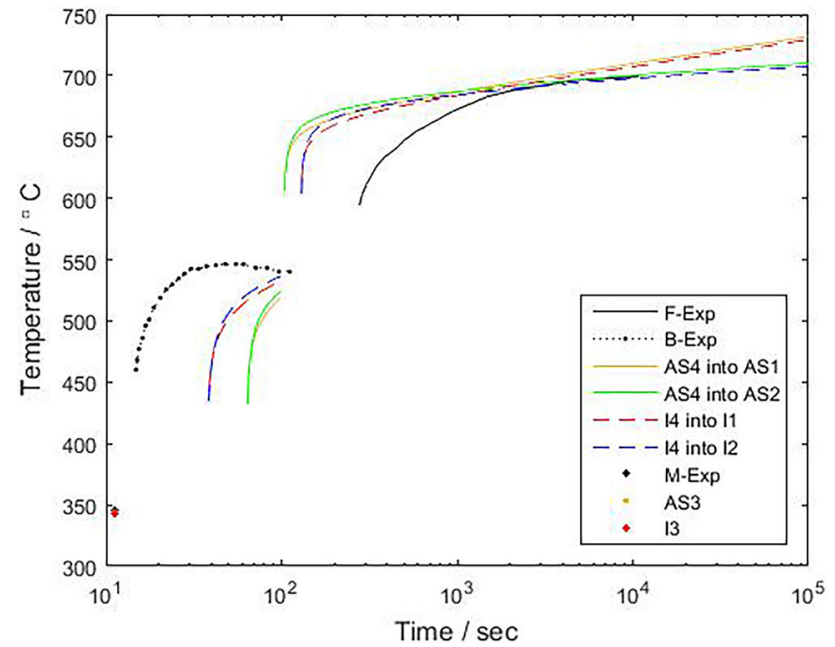

Fig. 11-Model validation for Sample id 29 with composition 0.3 pet C-0.69 pct Mn-0.38 pct Si-0.24 pct Mo-1.79 pct Ni-0.78 pct Cr.

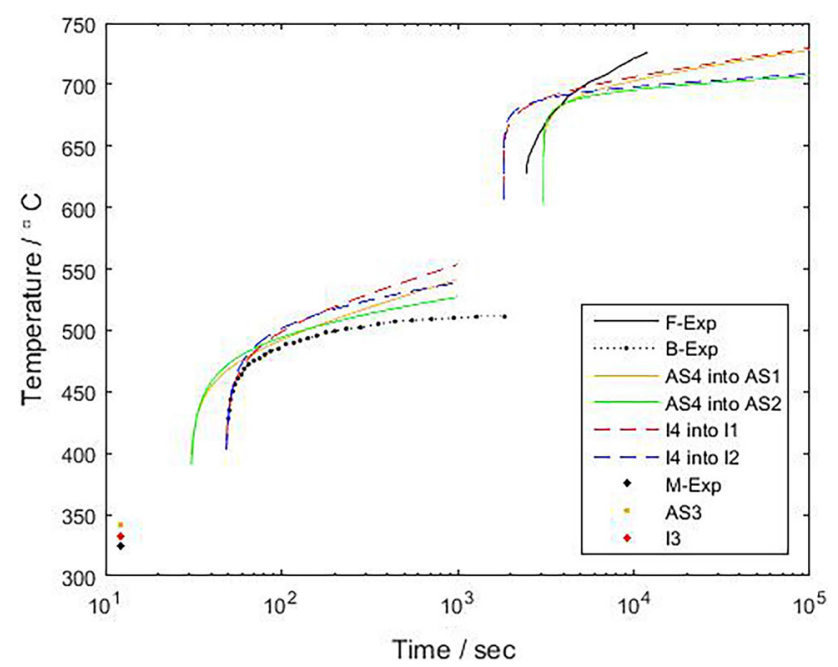

Fig. 12-Model validation for sample id 59 with composition 0.38 pet C-1.45 pet Mn-0.36 pct Si-0.76 pet Mo).

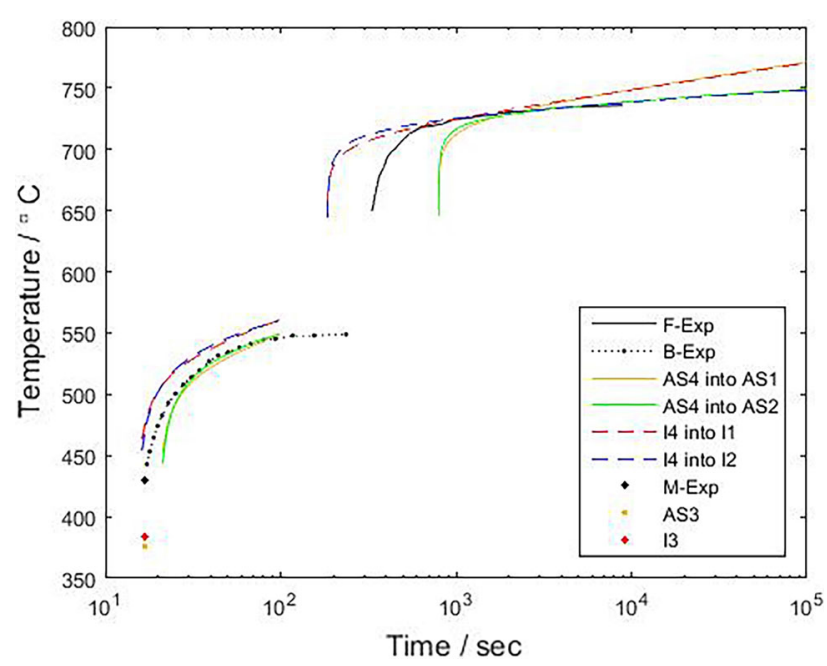

Fig. 13-Model validation for sample id 63 with composition 0.34 pet C-0.8 pet Mn-0.38 pet Si-0.78 pet Mo-0.34 pet Cr.

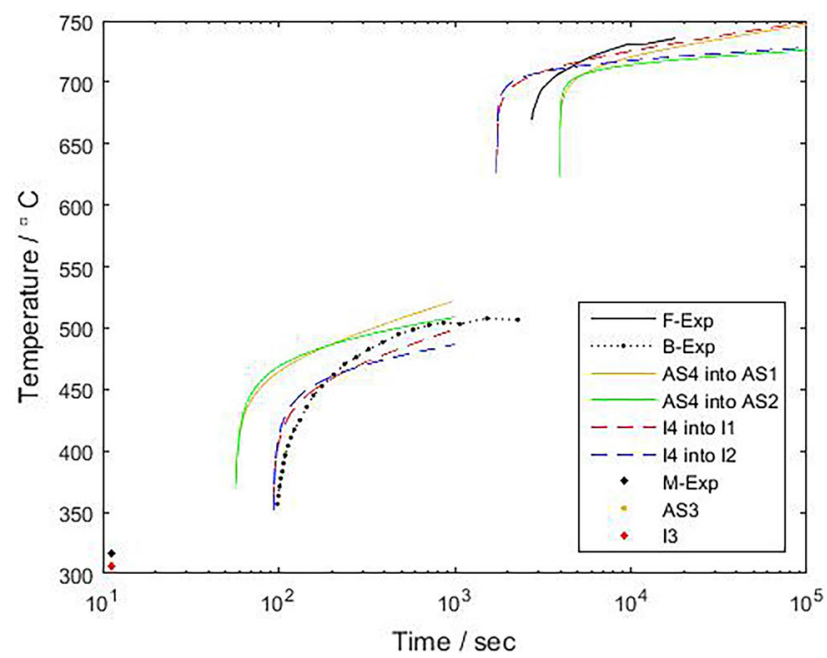

Fig. 14 -Model validation for sample id 66 with composition 0.4 pct C-1.38 pct Mn-1.5 pet Si-0.8 pct Mo. 


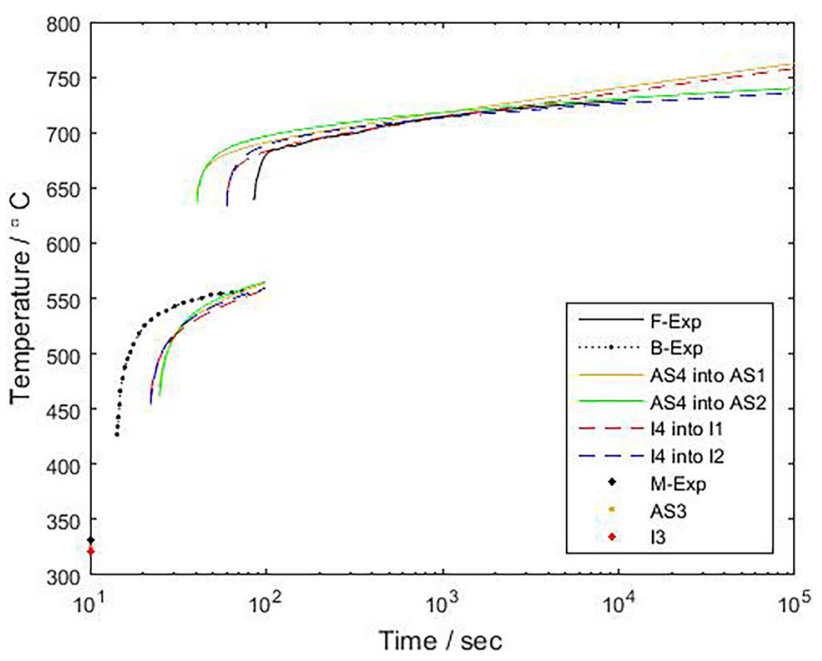

Fig. 15-Model validation for sample id 24 with composition 0.39 pet C-0.82 pet Mn-0.26 pet Si-0.21 pet Mo-1.0 pet Cr.

$$
\begin{aligned}
T_{m}= & 406.66-843.11 \mathrm{C}+528.00 \mathrm{Mn}-20.50 \mathrm{Si} \\
& -20.79 \mathrm{Ni}+20.55 \mathrm{Mo}-19.51 \mathrm{Cr}-250.93 \mathrm{Mn}^{2}
\end{aligned}
$$

where the alloying elements $(\mathrm{C}, \mathrm{Mn}, \mathrm{Si}, \mathrm{Ni}, \mathrm{Mo}, \mathrm{Cr}$, $\mathrm{B}, \mathrm{Co})$ are given in wt pct.

\section{ACKNOWLEDGMENTS}

Centre for Scientific and Technical Computing, National Institute for Mathematical Sciences hosted by Kwame Nkrumah University of Science and Technology Kumasi, Ghana. The University of Oulu under the research activity Genome of Steel project by the Academy of Finland. The authors thank Prof. David Porter at University of Oulu, Materials and Production Technology, Oulu, Finland, for his helpful discussion and insightful advice.

\section{REFERENCES}

1. E. Scheil: Archiv für das Eisenhüttenwesen, 1935, vol. 8, pp. 565-67.

2. M.T. Todinov: Metall. Mater. Trans. B, 1998, vol. 29B, pp. 26973.

3. J. Trzaska and L. Dobrzański: J. Mater. Process. Technol., 2007, vol. 192, pp. 504-10.

4. N. Saunders, Z. Guo, X. Li, A. Miodownik, and J.P. Schillé: JMatPro Software Literature, 2004.

5. J. Kirkaldy: in Proceedings of the International Conference on Phase Transformation in Ferrous Alloys, AIME, 1983.

6. A. Pohjonen, M. Somani, and D. Porter: Metals, 2018, vol. 8, p. 540 .

7. A. Pohjonen, M. Somani, J. Pyykkönen, J. Paananen, and D. Porter: in Key Engineering Materials, The Onset of the Austenite to Bainite Phase Transformation for Different Cooling Paths and Steel Compositions, Trans Tech Publ, 2016, vol. 716, pp. 368-75.

8. C. Kung and J. Rayment: Metall. Trans. A, 1982, vol. 13, pp. 328 31.

9. G.F.V. Voort: Atlas of Time-Temperature Diagrams for Irons and Steels, ASM International, 1991.
10. W.W. Cias: Austenite Transformation Kinetics of Ferrous Alloys, Climax Molybdenum Co, Greenwich, 1978.

11. H. Martin: PhD thesis, Kwame Nkrumah University of Science and Technology, Kumasi, Ghana, 2019, pp. 41-80.

12. M. Crowder: Int. Stat. Rev., 2009, vol. 77, pp. 148-49.

13. D. Hedeker and R.D. Gibbons: Longitudinal Data Analysis, Wiley, New York, 2006, vol. 451.

14. P.B. Baltes and J.R. Nesselroade: in Longitudinal Research in the Study of Behavior and Development, Academic Press, New York, 1979.

15. L.W. Sontag: Child Dev., 1971, vol. 42, pp. 987-1002.

16. A. Pohjonen, M. Somani, and D. Porter: Comput. Mater. Sci., 2018, vol. 150, pp. 244-51.

17. J. Wang, P.J. van der Wolk, and S. van der Zwaag: Mater. Trans. JIM, 2000, vol. 41, pp. 761-68.

18. M. Grossmann: Trans. AiME, 1942, vol. 150, p. 6.

19. P.D. Allison: Am. J. Sociol., 1977, vol. 83, pp. 144-53.

20. HO. Balli and BE. Sørensen: Empir. Econ., 2013, vol. 45, pp. 583-603.

21. AF. Hayes: Introduction to Mediation, Moderation, and Conditional Process Analysis : A Regression-Based Approach, Guilford Publications, New York, 2017.

22. A.K. Montoya: Behav. Res. Methods, 2019, vol. 51, pp. 61-82.

23. B.F. Braumoeller: Int. Org., 2004, vol. 58, pp. 807-20.

24. T. Brambor, W.R. Clark, and M. Golder: Polit. Anal., 2006, vol. 14 , pp. $63-82$.

25. A. Timoshenkov, P. Warczok, M. Albu, J. Klarner, E. Kozeschnik, G. Gruber, and C. Sommitsch: Steel Res. Int., 2014, vol. 85 , pp. 954-67.

26. A.A. dos Santos and R. Barbosa: Steel Res. Int., 2010, vol. 81, pp. 55-63.

27. W. Piekarska and D. Goszczyńska-Króliszewska: Procedia Eng., 2016, vol. 136, pp. 82-87.

28. Z.S.W. Piekarska and D. Goszczynska: Appl. Math. Comput. Mech., 2015, vol. 2, pp. 61-72.

29. D.P. Foster and R.A. Stine: J. Am. Stat. Assoc., 2004, vol. 99, pp. 303-13.

30. R.R. Hocking: Biometrics, 1976, vol. 32, pp. 1-49.

31. SAS/STAT software, SAS Institute Inc., version 9.4 ed, Cary, NC, USA, 2013.

32. H. Martin, A.O. Nunoo, and A.B.C. Dadson: in 27th Biennial Conference Proceeding, Ghana Science Association Improve the Ductility of Locally Manufactured Steel Rods by Tempering, Kumasi, Ghana, 2011.

33. R. Reed and H. Bhadeshia: Mater. Sci. Technol., 1992, vol. 8, pp. 421-36.

34. H. Bhadeshia: Met. Sci., 1982, vol. 16, pp. 159-66.

35. W. Bleck: in International Conference on TRIP-Aided High Strength Ferrous Alloys, Using the trip effect-the dawn of a promising group of cold formable steels, Ghent, Mainz/Aachen, 2002, pp. 13-23.

36. J. Miettinen, S. Koskenniska, M. Somani, S. Louhenkilpi, A. Pohjonen, J. Larkiola, and J. Kömi: Metall. Mater. Trans. B, 2019, vol. 50, pp. 2853-66.

37. P.J. Van Der Wolk: PhD thesis, Technical University of Delft, Delft, 2001, pp. 100-200.

38. M. Maalekian: Reportnr. 1, The Effects of Alloying Elements on Steels (I), Technische Universität Graz, 2007.

39. M. Ueno and T. Inoue: Trans. Iron Steel Inst. Jpn., 1973, vol. 13, pp. 210-17.

40. H.-S. Fang, J.-J. Wang, and Y.-K. Zheng: Metall. Mater. Trans. $A$, 1994, vol. 25, pp. 2001-07.

41. S. Liu, L. Yang, D. Zhu, and J. Zhang: Metall. Mater. Trans. A, 1994, vol. 25, pp. 1991-2000.

42. H. Aaronson, W. Reynolds, G. Shiflet, and G. Spanos: Metall. Trans. A, 1990, vol. 21, pp. 1343-80.

43. K. Oi, C. Lux, and G. Purdy: Acta Mater., 2000, vol. 48, pp. $2147-$ 55 .

44. S.K. Liu and J. Zhang: Metall. Trans. A, 1990, vol. 21, pp. $1517-$ 25.

45. P. Mangonon: Metall. Trans. A, 1976, vol. 7, pp. 1389-1400.

46. W. Piekarska and M. Kubiak: J. Therm. Anal. Calorim., 2012, vol. 110, pp. 159-66.

Publisher's Note Springer Nature remains neutral with regard to jurisdictional claims in published maps and institutional affiliations. 